\title{
Correction to: Enabling Sustainable Energy Transitions
}

\section{Correction to:}

Siddharth Sareen, Enabling Sustainable Energy Transitions, https://doi. org/10.1007/978-3-030-26891-6

This book was inadvertently published with the incorrect copyright holder "The Editor(s) (if applicable) and The Author(s), under exclusive licence to Springer Nature Switzerland AG". This has now been amended throughout the book to the correct copyright holder "The Editor(s) (if applicable) and The Author(s)".

The following sentence has been included in the Acknowledgment section.

Siddharth Sareen: "The author gratefully acknowledges funding from a University of Bergen postdoctoral research fellowship (financed by Bergen Research Foundation and University of Bergen-Equinor Akademia Agreement), the Open Access publication fund at the University of Bergen, the Strategic Programme for International Research Collaboration and the Faculty of Social Sciences at the University of Bergen."

Timothy Moss: "Gerda Henkel Foundation”

The updated version of the book can be found at https://doi.org/10.1007/978-3-030-26891-6

(C) The Author(s) 2020 
Christian Lund: "The research for this paper has benefitted from generous funding from the Danish Research Council and the European Research Council (ERC). ERC Grant: State Formation Through the Local Production of Property and Citizenship (Ares (2015)2785650 - ERC2014-AdG - 662770-Local State).” 